\title{
Changing Paradigms in Concepts on Dental Caries: Consequences for Oral Health Care
}

\author{
O. Fejerskov \\ Royal Dental College, Faculty of Health Sciences, University of Aarhus, Aarhus, Denmark
}

\author{
Key Words \\ Biofilms · Caries · Dental plaque · Fluoride · Preventive \\ dentistry
}

\begin{abstract}
Kuhn proposed in his Structure of Scientific Revolutions (1962) that the theoretical framework of a science (paradigm) determines how each generation of researchers construes a causal sequence. Paradigm change is infrequent and revolutionary; thereafter previous knowledge and ideas become partially redundant. This paper discusses two paradigms central to cariology. The first concerns the most successful caries-preventive agent: fluoride. When it was thought that fluoride had to be present during tooth mineralisation to 'improve' the biological apatite and the 'caries resistance' of the teeth, systemic fluoride administration was necessary for maximum benefit. Caries reduction therefore had to be balanced against increasing dental fluorosis. The 'caries resistance' concept was shown to be erroneous 25 years ago, but the new paradigm is not yet fully adopted in public health dentistry, so we still await real breakthroughs in more effective use of fluorides for caries prevention. The second paradigm is that caries is a transmittable, infectious disease: even one caused by specific microorganisms. This paradigm would require caries prevention by
\end{abstract}

\section{KARGER}

Fax +41613061234

E-Mail karger@karger.ch www.karger.com
(C) 2004 S. Karger AG, Basel

0008-6568/04/0383-0182\$21.00/0

Accessible online at:

www. karger.com/cre vaccination, but there is evidence that caries is not a classical infectious disease. Rather it results from an ecological shift in the tooth-surface biofilm, leading to a mineral imbalance between plaque fluid and tooth and hence net loss of tooth mineral. Therefore, caries belongs to common 'complex' or 'multifactorial' diseases, such as cancer, cardiovascular diseases, diabetes, in which many genetic, environmental and behavioural risk factors interact. The paper emphasises how these paradigm changes raise new research questions which need to be addressed to make caries prevention and treatment more cost-effective.

Copyright $@ 2004$ S. Karger AG, Basel

One of the buzzwords in the health sciences literature is 'evidence-based medicine'. The word 'evidence' is often used uncritically, implying that any written communication which has found its way into the scientific literature is considered as having a value of its own which adds to 'scientific knowledge'. Even when dealing with scientific contributions published in the most prestigious international journals it is important to appreciate that the evidence normally drawn on by scientists is dictated by an overriding contemporary paradigm. This concept was forcefully argued by Kuhn [1962/1970], who emphasised how a paradigm will shape the way in which any given
Ole Fejerskov

Royal Dental College, Faculty of Health Sciences

University of Aarhus, Vennelyst Boulevard

DK-8000 Aarhus C (Denmark)

Tel. +45 33181950, Fax +45 33150626, E-Mail of@dg.dk 
generation of researchers construes a causal sequence. The term 'paradigm' is in this case used to describe the guiding theoretical concepts of a science. In other words, a paradigm will form an umbrella under which a given discipline establishes a common view which often sets the rules and norms for how theories, methods etc. are handled in relation to the discipline. Moreover, results or data analysis and interpretations are conducted within the framework of the paradigm. Most established textbooks within a given discipline bring the paradigms in a 'digested form' to the next generations of students and young researchers and they often falsely give a younger generation the impression that scientific growth within a given discipline has the character of a progressive march towards a complete understanding of 'reality'.

Science is an exquisite blend of data and theory, fact and hypotheses, observations and views, which in most disciplines at any given time are embedded in a particular paradigm.

The aim of this paper is to demonstrate how such paradigms play an important role in cariology. The paper will first focus on how paradigms in general influence science. Then two paradigms dominating cariology during the past half century will be presented and it will be argued why scientific revolutions - shifts in paradigms - are needed in order to advance new knowledge and improve health in populations. Finally, the impact of such revolutions on cariology and oral health will be presented and the consequences for immediate future research activities will be discussed.

\section{Paradigms and Science}

History shows that the development of science has always been highly influenced by paradigms, and revolutionary shifts in paradigms have not easily been brought about [for famous examples see Kuhn, 1962/1970].

When a scientific theory or concept has become a paradigm, this is only dismissed once an alternative paradigm can replace it, in a scientific revolution. The interesting point is that a paradigm is rarely challenged in such a way that attempts are made to falsify it by direct comparison with the particular events or diseases that are studied. Of course this does not mean that scientists do not reject scientific theory. All it shows is that when this happens, such rejections are always in need of finding a new paradigm in order to facilitate the shift.

A transition from one paradigm to another is not a cumulative process or a process in which one just expands on the old paradigm in order to have an impact on research or health activities. Rather a transition necessitates a reconstruction of the field which significantly changes some of the discipline's most basic theoretical generalisations as well as rejecting several of the methods and interpretations performed in the past. It should be appreciated that very often it is the same set of data which constituted the basis for the old paradigm that is reconsidered, and a new interpretation or paradigm is built on more or less the same set of data. Therefore, it is common to see within the same field the old and the new paradigms living side by side for a substantial period of time. This is because two or more groups of researchers apparently work in 'different worlds' where they study different phenomena although they are standing in the same place and are looking in the same direction. However, it is obvious that they do not see the same 'world'. In certain areas they are definitely seeing different things (things they are looking for simply as a result of the paradigm), but they may equally well see the same phenomena although in a different relative context. This is one of the good reasons why some cannot even consider a causal relationship, which appears intuitively obvious to others.

Moreover, this obvious discrepancy between different paradigms is often further enhanced by the fact that even within disciplines communication across revolutionary gaps is very incomplete. Researchers may use similar words, but in reality define them rather differently.

More than half a century passed before Newton's Principia was generally accepted. Also Darwin [1889] wrote in the Origin of Species that he by no means expected to be able to convince other scientists of his views, but that only in the future, when a new generation of researchers grew up, would they be able to appreciate his observations. Max Planck [1940] emphasised that a new scientific truth does not convince its opponents, but only gains strength because its opponents gradually die out. Thus a characteristic aspect of science is the maintenance of a resistance towards changes in paradigms, in particular from those whose careers have been based on existing paradigms. Prestigious institutions or international bodies will often have made strong stands in terms of 'scientific documentation and subsequent recommendations'. For such bodies a new paradigm will be seen as a threat and resistance will be based on the concept that the old established paradigm would be able to explain the phenomena studied so that "nature can be put into the box built by the paradigm'.

In the following these thoughts should be kept in mind because - when dealing with diseases - paradigms will 
inevitably have a decisive influence on how we diagnose, prevent and treat a disease. When considering dental caries this is certainly the case.

\section{Fluoride and Dental Caries}

Fluorides play a key role in the prevention and control of dental caries. There is no doubt that the discovery of the anti-cariogenic properties of fluoride was one of the most important landmarks in the history of dentistry. The history of the old and the new paradigms explaining the possible causal effects of fluoride on teeth (and bone) represents an excellent example of the need for changing concepts in medicine in order to improve health.

In the 1930s experimental animal studies and human epidemiological studies established both the association and the cause-and-effect relationship between fluoride in drinking water and mottled enamel (dental fluorosis) [for reviews see Fejerskov et al., 1977, 1994]. In addition, the presence of fluoride in water supplies was associated with a lower prevalence of dental caries [Dean, 1946]. It was thus reasonable to conclude that ingestion of fluoride was important to reduce the number of cavities in teeth while at the same time affecting enamel formation, so that Dean [1946] could conclude that '... amounts not exceeding 1 part per million expressed in terms of fluorine $(F)$ are of no public health significance'. The focus from then on was to explain how children born and reared in communities with about $1 \mathrm{ppm}$ fluoride in water supplies could have about 50\% less cavities than expected [Arnold et al., 1956; Backer Dirks, 1974].

The toxic effects of fluoride on amelogenesis were thought to be a result of the secretory ameloblasts being particularly susceptible to fluoride [for review see Fejerskov et al., 1977]. This concept prevailed until experimental studies in pigs showed that dental fluorosis can develop by only affecting the maturation stage of amelogenesis [Richards et al., 1986]. This new understanding resulted in extensive research on chemical, biochemical, and cellular events during enamel maturation [Smith, 1998], but we are still far from understanding how fluoride affects mineralising dental tissues [Aoba and Fejerskov, 2002].

The paradigm on how fluoride 'prevents dental caries' resulted from the following line of thinking. Teeth formed in areas with a fluoride content of about $1 \mathrm{ppm}$ in water supplies have an increased fluoride content in surface enamel [Brudevold et al., 1956; Isaac et al., 1958]. Fluorine is the most electronegative of the elements and has a strong affinity for exchange with hydroxyl ion in hydroxy- apatite [Kay et al., 1964; Elliott, 1969]. The electrostatic attraction between $\mathrm{Ca}^{2+}$ and the $\mathrm{F}^{-}$will be greater than between $\mathrm{Ca}^{2+}$ and $\mathrm{OH}^{-}$, making the fluoridated apatite lattice more crystalline [Zipkin et al., 1962; Newsely et al., 1963; Frazier et al., 1967] and more stable. As a consequence it is less soluble in acid [Volker, 1939; Kutnerian and Kuyper, 1957; Young, 1975; Brown et al., 1977].

By combining these data it is understandable how the paradigm of fluoride 'making teeth more resistant to caries attack' became established, and then for more than half a century entirely influenced caries prevention and research. The hypothesis was that increased intake of fluoride during tooth formation raises the fluoride concentration in enamel and hence increases acid resistance. As a consequence fluoride had to be taken systemically and artificial fluoridation of drinking waters became the 'optimal' solution. If this could not be achieved fluoride should be ingested in the form of tablets, vitamin drops, lozenges, salt, added to milk, etc.

As ingestion of increasing amounts of fluoride during tooth mineralisation results in a gradual hypomineralisation of the final outer enamel [Fejerskov et al., 1974, 1975, 1994], not least the public health-oriented sections of the dental profession downplayed the toxicological properties of fluorides. Thus diagnosis of early stages of dental fluorosis was questioned (or even ignored). Dean's [1946] original data interpretation was incorrectly referred to. Early signs of dental fluorosis were described as 'pearl like' teeth to be considered normal, whereas fully matured enamel with its yellowish colour was characterised as 'fluoride-deficient teeth'. In some parts of the world fluoride was added to school drinking water in excessive amounts based on the philosophy that 'if little is good (to reduce decay) more is better'.

In other words, it is apparent that this predominant paradigm fully involved all the general features of scientific paradigms described in the scientific literature [Kuhn, 1962/1970]. Likewise, the scientific revolution leading to the new paradigm also followed the abovedescribed general path of development.

Dean's [1946] data are unique and often confirmed. The effect of fluoride on appetite crystallinity and stability is unquestionable. Artificial water fluoridation in populations with a substantial caries prevalence results in marked reductions in dental cavities [Arnold et al., 1953, 1962; Backer Dirks et al., 1961; Brunelle and Carlos, 1990]. But could it be that fluoride affects the caries process in a way entirely different from what the paradigm claimed? If so, may we then develop new and more effective ways of using fluorides? Reinterpretion of the avail- 
able data combined with new studies led to the scientific revolution as follows:

Deciduous teeth from a fluoride area contain much less fluoride in enamel than permanent teeth both from a 1 -ppm fluoride area and a very low $(<0.2 \mathrm{ppm} F)$ area [Mellberg, 1977], but the systemic effect on caries prevalence is the same in both dentitions irrespective of fluoride incorporated during tooth formation [Thylstrup, 1979]. The difference in fluoride concentration in surface enamel between permanent teeth from low-fluoride and fluoridated areas is very limited [Brudevold et al., 1956; Isaac et al., 1958; Mellberg, 1977; Kidd et al., 1980; Larsen et al., 1986; Richards et al., 1989]. It is hardly likely that such a small difference should explain a $50 \%$ reduction in cavities. Complete substitution of $\mathrm{OH}^{-}$in human enamel corresponds to a fluoride content of $3.7 \%$ (about $39,000 \mathrm{ppm})$. Even in the most severe cases of human dental fluorosis ever analysed, less than one quarter of the $\mathrm{OH}^{-}$(about 10,000 ppm F) have been replaced by $\mathrm{F}$ [Richards et al., 1992].

It has not been possible to demonstrate a clear-cut inverse relationship between fluoride content of surface enamel and dental caries [DePaola et al., 1975; Poulsen and Larsen, 1975; Richards et al., 1977; Schamschula et al., 1979; Spector and Curzon, 1979]. In vitro experimental caries using gel techniques has shown exactly similar degrees of lesion development in teeth from low- and 'optimal'-fluoride areas [Kidd et al., 1980] and shark enamel containing fluorapatite develops caries lesions in an in situ model [Ögaard et al., 1988]. Such a thing as relative resistance of enamel to caries attack does not exist [Weatherell et al., 1984], and Brudevold et al. [1965] and Brown et al. [1977] have stressed that the rate of acid solubility is of little importance in protecting the tooth against caries.

Clinical observations show that children having their teeth formed and mineralised before moving into a fluoridated region experience a significant reduction in dental caries prevalence [Arnold, 1957]. This author was probably the first to mention that water-borne fluoride has a posteruptive cariostatic effect. This so-called 'topical' effect was for very long claimed to be inferior to the postulated 'systemic effect' and subsequent clinical trials appeared to show that the capacity of topical fluoride to reduce caries was disappointingly lower $(20-30 \%$ reduction) than that of the about $50 \%$ reduction by water fluoridation. The apparently lower efficacy of topical fluorides, however, was most likely a result of unfair comparison between results of several short-term (1-3 years) clinical trials with a result of water fluoridation programmes lasting for more than 10 years.
The fact that a cariostatic effect of fluoride could be obtained without a concomitant increase of fluoride in sound enamel [Brudevold et al., 1967; Aasenden et al., 1972; Shern et al., 1977] whereas enamel fluoride concentration increased in enamel undergoing a carious challenge [Hallsworth et al., 1971; Richards et al., 1977] became very important. By combining the above data with the results from theoretical and laboratory experiments on enamel solubility [Larsen, 1975; Larsen et al., 1976] it was tempting to suggest 'a possible explanation of the predominant cariostatic effect of fluoride' in 1981 [Fejerskov et al., 1981].

This new paradigm was a result of a concomitant reconsideration of the pathogenesis of dental caries lesions. Hitherto, dental caries was always recorded in epidemiological studies as cavities. As such, all clinical measurements (the DMFT/S) only comprised very late stages in the caries process (fig. 2). Thereby it was ignored that a clinically detectable lesion (even the non-cavitated white spot) is a result of innumerable $\mathrm{pH}$ fluctuations in the microbiota covering the enamel. The enamel surface is a sponge, which by no means is chemically inert. The constantly ongoing $\mathrm{pH}$ fluctuations taking place even in socalled 'resting plaque' [Küseler et al., 1993; Baelum et al., 1994], and dramatically enhanced during exposure to fermentable carbohydrates [Stephan, 1940; Fejerskov et al., 1992], will be associated with chemical exchange reactions between the tooth mineral and the surrounding plaque fluid [Margolis et al., 1988]. We therefore proposed that 'the major reason for the cariostatic effect of fluoride can be ascribed to its ability to influence these processes, even at very low $(0.2-1 \mathrm{ppm}) \mathrm{F}$ concentrations by facilitating calcium phosphate precipitation' [Fejerskov et al., 1981]. This was in accord with Brudevold et al. [1965], who suggested that the role of fluoride in caries prevention could be ascribed to its unique ability to induce apatite formation from solutions of calcium and phosphate. Because of saliva's inorganic composition [Andresen, 1921; Koulourides et al., 1965] it is an excellent fluid for 'remineralisation', and fluoride in slightly elevated concentrations enhances this potential as $\mathrm{pH}$ is lowered [Larsen, 1975]. The simplistic 'story' about 'remineralisation' was a reality.

Moreover, it was remarkable that only traces of fluoride are required in a solution with calcium present at $\mathrm{pH}$ 4.2 to reduce markedly the rate of dissolution of enamel [Manley and Harrington, 1959; Larsen et al., 1976], as theoretically convincingly illustrated by ten Cate and Duijsters [1983]. So, in 1981, we concluded that 'what appears to be important in reducing the solubility of the 
enamel is the fluoride ion activity in the oral fluid rather than a high content of fluoride in enamel' [Fejerskov et al., 1981].

When these ways of interpreting available data were first presented in a comprehensive way (at an IADR symposium in Osaka, Japan, in 1981) the reaction was extremely vigorous from parts of the predominantly public health-oriented research community. This was - seen in retrospect - in full accord with the way in which paradigm shifts have been received in the history of science [Kuhn, 1962/1970].

By 1981 it was still a question if the new paradigm could be verified by clinical/epidemiological data. Therefore Groeneveld [1985] re-examined the meticulously collected caries data obtained from the well-controlled Dutch water fluoridation study in Tiel-Culemborg in the 1950s [Backer Dirks et al., 1961]. He could demonstrate that, when both enamel and dentine lesions where diagnosed, there was virtually no difference in the total number of lesions between fluoridated and non-fluoridated areas. However, when only dental lesions (cavities) were recorded, the 'expected' reduction of about 50\% was found. Thus, the data could be explained as a result of fluoride in the oral environment affecting the dissolution/ reprecipitation processes in the tooth to retard the rate of lesion progression as predicted by the new paradigm. Groeneveld and Backer Dirks [1988] concluded that 'on the initiation of a caries lesion no pre- nor posteruptive effect of fluoride can be observed. In fact apart from a small retardation of new lesions at younger ages there is almost no effect at all. However, retardation of the progression into dentinal lesions is far more pronounced'. Moreover, despite the fact that in fluoridated areas there is a higher concentration in the fluoride in the outer enamel layers, the difference in prevalence of lesions is so small between fluoride and non-fluoride areas that the conclusion that 'fluoride concentration in the enamel plays a role of minor importance in caries reduction $[\mathrm{Fe}-$ jerskov et al., 1981]' is justified [Groeneveld and Backer Dirks, 1988]. A very impressive and open-minded conclusion drawn by one of the most prominent fluoride researchers in the history of ORCA during half a century.

\section{Dental Caries - an Infectious Disease?}

The above scientific revolution in fluoride research was partly brought about because the natural history of caries lesion development was reconsidered. Let us, therefore, in the following consider if a paradigm shift also is going on in our understanding of dental caries as a disease.

The use of the concept 'an infectious disease' immediately signals that a disease is caused by a particular microorganism or agent, which has 'infected' an individual. Or, as defined by Last [1995], who uses infectious disease synonymously with communicable disease: 'an illness due to a specific infectious agent or its toxic products that arises though transmission of that agent or its products from an infected person, animal or reservoir to a susceptible host...'. For about half a century caries was defined as an 'infectious and transmittable' disease on the following premises.

Not all types of microorganisms in the oral cavity are equally able to ferment carbohydrates, so it has been logical to look for major caries pathogens. While research in the first half of the previous century focused on the role of Lactobacillus [Rodriques, 1931], the latter half of that century focussed on the role of mutans streptococci [van Houte, 1980; Loesche, 1986; Bowden, 1991].

The concept of dental caries being infectious and transmittable' grew out of the elegant rodent studies performed in the 1950s [Keyes, 1960]. Caries only developed in rodents when they were caged with or ate the faecal pellets of groups of caries-active rodents. Further proof emerged when certain streptococci isolated from caries lesions in hamsters, unlike other types of streptococci, caused rampant decay in previously caries-inactive animals [Fitzgerald and Keyes, 1960]. These bacteria, later identified as Streptococcus mutans (SM), gave rise to the concept of caries being due to a specific infection with mutans streptococci, a concept that has gained wide support within the field of caries microbiology over the past four decades [Loesche, 1986; Tanzer, 1989].

It is occasionally claimed that because SM cannot be detected in some patients with no caries increment this is a 'proof' that you need to be 'infected' with SM to get a lesion. It is ignored that in patients with excellent oral hygiene there is virtually no 'plaque' on the tooth surfaces and therefore SM may be below detection level. This should be combined with the fact that mutans streptococci are not primary colonisers of tooth surfaces [Nyvad and Kilian, 1990].

Mutans streptococci belong to the resident microflora and are ubiquitous in populations worldwide. The relationship between SM and dental caries is not absolute. Relatively high proportions of SM may persist on tooth surfaces without caries progression while caries may develop also in the absence of these species [Marsh and Martin, 1992]. The presence of SM can explain only about 
$6-10 \%$ of the caries experience in a given population [Sullivan et al., 1989; Granath et al.,1993]. The level of mutans streptococci in saliva of children cannot predict future carious increments in children [Matee et al., 1993] and high salivary mutans-streptococcal counts do not add to the prediction when combined with conventional caries experience parameters [van Palenstein Heldermann et al., 2001]. The number of mutans streptococci or lactobacilli in plaque does not explain the variation in caries experience [Sullivan et al., 1996]. A dramatic decline in caries experience has been documented over a few years in populations without apparent changes in salivary mutans levels in the population [Bjarnason et al., 1994].

Collectively, these observations imply that mutans streptococci do not play a specific role in dental caries. Rather, the outgrowth of mutans streptococci should be explained by a disturbance of the homeostasis in the dental biofilm. If the homeostasis of the oral microflora is lost, then an opportunistic infection can occur, i.e., these infections are derived from microorganisms that are endogenous to the host [Marsh and Martin, 1992] and an ecological plaque hypothesis seems more attractive [Marsh, 1994].

\section{Dental Caries - a Biofilm-Induced Disease}

It is not merely semantics, but a paradigm shift, to consider dental caries as a 'complex disease caused by an imbalance in physiologic equilibrium between tooth mineral and biofilm fluid' [Fejerskov and Nyvad, 2003]. However, it is acknowledged, as stressed by Davies [2003], that biofilms according to an NIH announcement account for over $80 \%$ of microbial infections in the body. Therefore dental caries is of course microbially induced, but the important point is that it is by endogenous bacteria - not exogenous, specific bacteria which infect the individual.

The resident flora in the oral cavity will inevitably form biofilms on teeth, e.g. a biofilm defined as a population or community of bacteria living in organised structures at an interface between a solid and liquid. Biofilm bacteria live in microcolonies encapsulated in a matrix of extracellular polymeric substances. Although fixation and dehydration techniques during processing of biofilms for transmission electron microscopy result in shrinkage of the tissue to a varying extent, it has for many years been appreciated that oral biofilms vary extensively in structural arrangement with the colonies deep within the biomass being densely packed, and often being separated by loosely packed bacteria and larger 'empty' pathways. Confocal laser scanning microscopy of biofilms in general has revealed that the biomass comprises 'open' water channels through which nutrients and metabolic waste products sieve [Laurence and Neu, 1999]. From dealing with 'oral debris' and later 'dental plaque' we now appreciate that within an oral biofilm, each group of bacteria occupies microenvironments, which are determined by surrounding cells, proximity to the larger diffusion pathways, the distance from the outer surface, etc., all of which are likely to determine $\mathrm{pH}$, availability of nutrient, relative degrees of saturation of calcium phosphates, etc.

Most studies in caries microbiology have dealt with cells in the planktonic phase. It has only recently been appreciated that the same bacteria attached to surfaces and forming biofilms may respond significantly differently to a variety of stimuli such as antimicrobial agents [for review see Davies, 2003]. Many organisms can respond with considerable flexibility to a changing environment; a single set of genes can generate a range of characteristics or phenotypes depending on the environment. With this new general knowledge on biofilm physiology and the appreciation of the fact that the rate of oral biofilm formation and its structural composition vary substantially between individuals [Nyvad and Fejerskov, 1989], not to mention that biofilm 'age' may play a decisive role in the response to stimuli, it will be obvious that we need renewed research on oral biofilm physiology in relation to stages of progression of oral diseases (caries, gingivitis and periodontal loss of attachment). Dental plaque is an established designation for any clinically detected microbial mass in the dentition, but it is probably not immediately synonymous with oral biofilm.

The paradigm claiming the biofilm as the cause of dental caries has several implications. Lesions develop where biofilms are allowed to mature and remain for prolonged periods of time. Therefore, dental caries occurs at occlusal surfaces (being particularly at risk during the long-lasting eruption into functional occlusion), in interproximal areas below contact points/facets, and along the marginal gingiva. Once exposed, the enamel-cementum junction of course represents an obvious 'retention site'. Depending on the environmental conditions in the oral cavity, of the individual in general, or at specific sites within an individual, the physiological equilibrium between tooth and biofilm may be disturbed, resulting in a net loss of mineral. If a frank cavity is allowed to form, such a site represents an ecological niche where the biofilm composition gradually adapts to a declining $\mathrm{pH}$ environment. Within cavities the biofilm metabolism and diffusion characteris- 
Fig. 1. Schematic illustration of the relationship between the aetiological factor - the microbial deposit and the tooth and biological determinants (inner circle) which influence lesion development at the single tooth surface. In the outer circle are listed various behavioural and socio-economic factors (or confounders) which influence the likelihood for lesion development at an individual and population level. Modified from Fejerskov and Manji [1990].

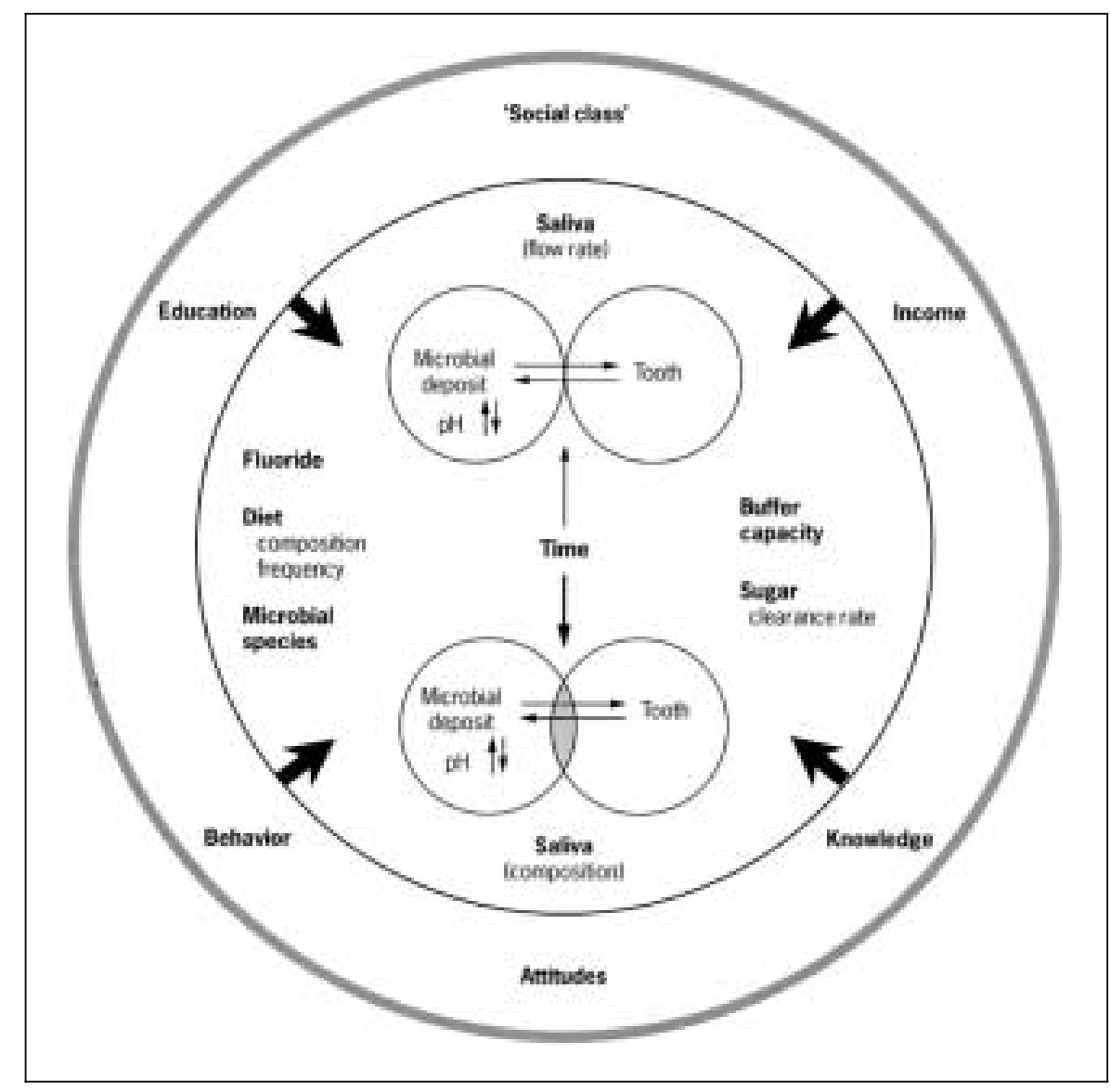

tics are significantly different from those of biofilm covering sound or inactive caries surfaces [Fejerskov et al., 1992]. Once this is appreciated, the complex character of the disease is highly relevant as numerous biological factors may influence the likely outcome at the single site and in the individual as a whole.

In the schematic illustration (fig. 1) the complex interplay between saliva, dietary habits, and the many biological determinants determine biofilm composition and metabolism. In concert with innumerable other factors (several of which we do not even know about yet), the oral and biofilm fluids will determine the likelihood for a net loss of mineral and the rate at which this occurs at any given site. At the individual as well as the population level many of these variables (oral hygiene, diet, etc.) will be highly influenced by the behavioural and socio-economic conditions prevailing.

Once this concept of the complexity of the disease and its manifestations is appreciated it will be fully understood why it is so difficult to interpret data about associa- tions concerning dental caries, and why no good predictor models are available [Hausen, 1997].

\section{Conclusion and Implications for Oral Research, Prevention and Clinical Management of Dental Caries}

The two scientific revolutions (paradigm shifts) in cariology which are described in this paper necessitate a substantial rethinking of the design of future research projects in terms of data analysis and interpretation, and in advancement of new prevention and treatment strategies for dental caries.

By appreciating that dental caries belongs to the group of common diseases considered as 'complex' or 'mulifactorial' such as cancer, heart diseases, diabetes, and certain psychiatric illnesses, we have to realise that there is no simple causation pathway. It is not a simplistic problem such as 'elimination of one type of microorganism', or a 
Fig. 2. Schematic illustration of the concept of dental caries as conceived in this paper. Because of continuous exposure to the metabolically active biofilm disease control must be maintained lifelong [Fejerskov and $\mathrm{Ny}$ vad, 2003].

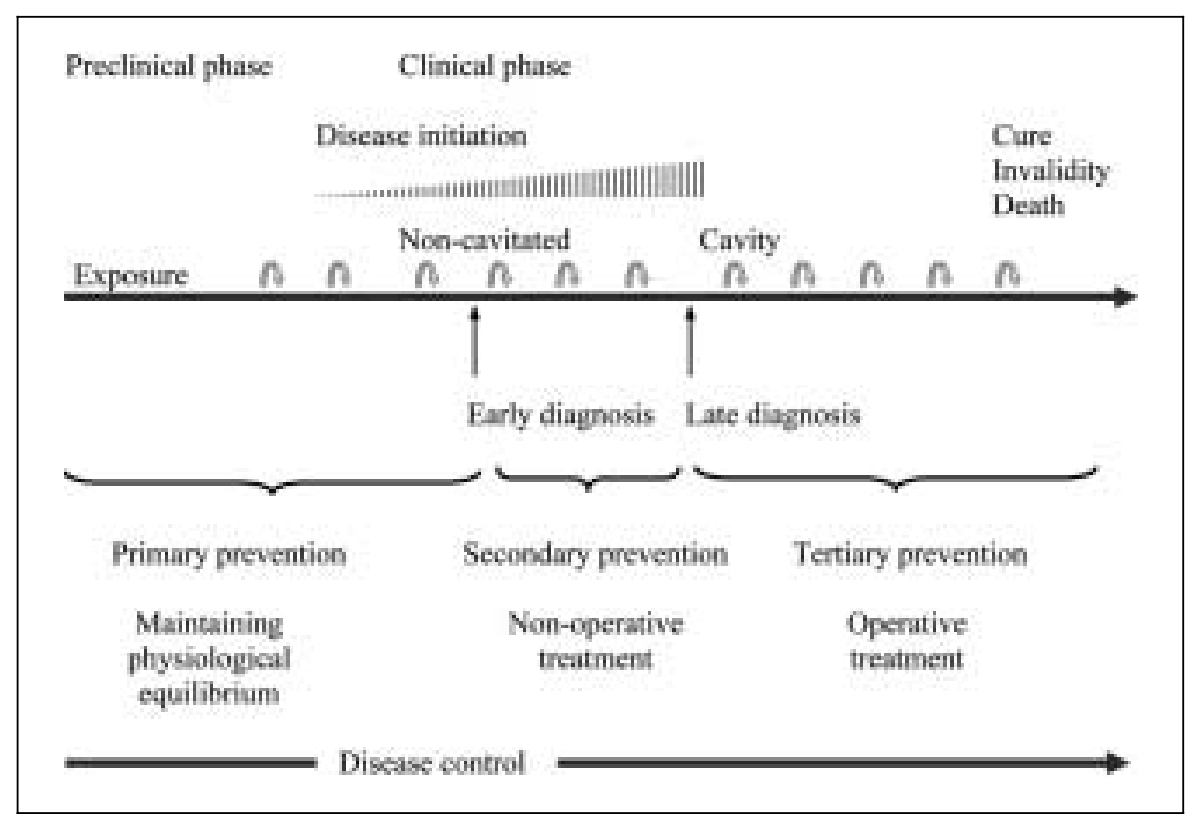

matter of improving 'tooth resistance'. Complex diseases cannot be ascribed to mutations in a single gene or to a single environmental factor. Rather they arise from the concerted action of many genes, environmental factors, and risk-conferring behaviours. As stressed recently by Kiberstis and Roberts [2002], one of the greatest challenges facing biomedical researchers today is to sort out how these contributing factors interact in a way that translates into effective strategies for disease diagnosis, prevention and therapy.

Let us keep in mind that dental caries is ubiquitous in all populations [Fejerskov and Baelum, 1998], but the incidence rate varies greatly within and between populations. It is important to appreciate that the caries incidence rate in a group of individuals appears fairly constant throughout life if no special efforts to control lesion progression are made [Hand et al., 1988; Luan et al., 2000]. These new paradigms help to explain the nature of lesion initiation and progression and accordingly why dental caries cannot truly be 'prevented', but rather 'controlled' by a multitude of interventions.

Figure 2 schematically illustrates the concept of dental caries as presented in this paper and explains why dental caries has to be controlled lifelong if a functional dentition is to be maintained. From the figure it will also be appreciated that diagnosis should be performed at non-cavitated stages because the dynamic nature of lesion progression allows for arrest of further mineral loss by restoring physiological equilibrium between tooth mineral and oral fluids. The whole concept of non-operative treatment has its rationale in these new paradigms, and it will be apparent why any restorative treatment must be accompanied by simultaneous disease control at the individual level.

A consequence of dental caries being a complex disease will be that on a population basis we may have success with a particular 'preventive programme' in one population in one country, but not necessarily in another population in another country with different cultural and behavioural habits. Moreover, we may organise our dental health care very differently in neighbouring countries, and apply fluorides in very different ways (mouth rinsing, toothpaste, water fluoridation and supervised brushing etc.) and obtain rather similar caries reductions as exemplified by comparing the Scandinavian countries. There is no one single 'programme' to be superimposed uncritically on all populations - the important question remains how to control caries lesion progression as cost-effectively as possible. These new concepts explain why we have experienced that several of the 'old' recommended preventive programmes are no longer effective. It is of course not because the agents we used in prevention are no longer efficacious. They just become ineffective because the caries incidence rate has changed as the environment has changed.

At the individual patient level we have successfully 'controlled' the physiologic balance of the intra-oral envi- 
ronment with topical fluorides, dietary monitoring, 'plaque control', etc., but the well-trained clinician knows that some patients require much more and 'closer' monitoring than others to avoid new lesions. The consequence of the paradigms is to appreciate that the risk of developing new lesions is never zero. Therefore dental caries can never be $100 \%$ preventable at the individual and much less at the societal level because of its complex nature. Dental caries is as old as mankind.

Whatever directions caries research should take from here it will require a multidisciplinary approach to solving complex problems. More than ever, well-educated clinical dentists should set the stage and in collaboration with colleagues trained in the multitude of new fields in the basic sciences (biophysics, functional genomics, proteomics, chemical biology, nano-technology, etc.) address clinically relevant questions. Let ORCA remain the forum - marketplace, if you like - where clinical dentistry meets basic sciences in fruitful and challenging exchange of new knowledge to the benefit of the health of populations.

History has shown that European caries research has an intellectual flexibility and scientific creativity which allows for ongoing stimulating debates. Let ORCA benefit from this by encouraging more in-depth scientific debates in conjunction with its meetings in the future. Let us bear Charles Darwin's dictum in mind: 'All observations must be for or against some view to be of any service'. Let the discussion in ORCA be fearless in conceptual daring, but humble in its respect for observation and facts.

\section{Acknowledgements}

The present paper would not have been possible without the many discussions and close collaboration over many years with: Vibeke Baelum, G. Dahlén, M.J. Larsen, F. Manji, Bente Nyvad, A. Richards and A. Thylstrup to all of whom I am very grateful.

\section{References}

Aasenden R, DePaola PF, Brudevold F: Effects of daily rinsing and ingestion of fluoride solutions upon dental caries and enamel fluoride. Arch Oral Biol 1972; 17:1705-1714.

Andresen V: Über Mineralisation und Remineralisation des Zahnschmelzes. Dtsch Monatsschr Zahnheilkd 1921;39:97-122.

Aoba T, Fejerskov O: Dental fluorosis: Chemistry and biology. Crit Rev Oral Biol Med 2002;13: 155-171.

Arnold FA Jr: The use of fluoride compounds for the prevention of dental caries. Int Dent $\mathrm{J}$ 1957;7:54-72

Arnold FA Jr, Dean HT, Jay P, Knutson JW: Effects of fluoridated water supplies on dental caries prevalence: 10th year of the Grants Rapids-Muskegon Study. Public Health Rep 1956; 71:652-658.

Arnold FA Jr, Dean HT, Knutson JW: Effect of fluoridated public water supplies on dental caries incidence: Results of the seventh year of study at Grand Rapids and Muskegon, Mich. Public Health Rep 1953;68:141-148.

Arnold FA Jr, Likins RC, Russell AL, Scott DB Fifteenth year of the Grand Rapids fluoridation study. J Am Dent Assoc 1962;65:780785.

Backer Dirks O: The benefits of water fluoridation. Caries Res 1974;8:2-15.

Backer Dirks O, Houwink B, Kwant GW: The results of $61 / 2$ years of artificial drinking water in The Netherlands: The Tiel-Culemborg experiment. Arch Oral Biol 1961;5:284-300.

Baelum V, Fejerskov O, Küseler A: Approximal plaque $\mathrm{pH}$ following topical applications of standard buffers in vivo. Caries Res 1994;28 116-122.
Bjarnason SS, Finnbogason SY, Holbrook P, Köhler B: Caries experience in Icelandic 12-yearold urban children 1984 and 1991. Community Dent Oral Epidemiol 1994;21:194-197.

Bowden GHW: Which bacteria are cariogenic in humans?; in Johnson NW (ed): Risk Markers for Oral Diseases: Dental Caries. Cambridge, Cambridge University Press, 1991, pp 266286.

Brown WE, Gregory TM, Chow LC: Effects of fluoride on enamel solubility and cariostasis. Caries Res 1977;11:118-141.

Brudevold F, Gardner DE, Smith F: The distribution of fluoride in human enamel. J Dent Res 1956;35:420-429.

Brudevold F, McCann HG, Grøn P: Caries resistance as related to the chemistry of the enamel; in Wolstenholme GEW, O'Connor M (eds): Caries Resistant Teeth. Ciba Found Symp. London, Churchill, 1965, pp 121-148.

Brudevold F, McCann HG, Nilsson R, Richardson B, Coklica V: The chemistry of caries inhibition: Problems and challenges in topical treatments. J Dent Res 1967;46:37-45.

Brunelle JA, Carlos JP: Recent trends in dental caries in US children and the effect of water fluoridation. J Dent Res 1990;69(special issue):723727.

ten Cate JM, Duijsters PPE: Influence of fluoride in solution on tooth demineralisation. I. Chemical data. Caries Res 1983;17:193-199.

Darwin C: On the Origin of Species. New York, 1889.

Davies D: Understanding biofilm resistance to antibacterial agents. Nat Rev 2003;2:114-122.
Dean HT: Epidemiological studies in the United States; in Moulton R (ed): Dental Caries and Fluorine. Washington, American Association for the Advancement of Science, 1946, pp 531

DePaola PF, Brudevold F, Aasenden R, Moreno EC, Englander H, Bakhos Y, Bookstein F, Warram J: A pilot study of the relationship between caries experience and surface enamel fluoride in man. Arch Oral Biol 1975;20:859-864.

Elliott JC: Recent progress in the chemistry, crystal chemistry and structure of the apatite. Calcif Tissue Res 1969;3:293-307.

Fejerskov O, Baelum V: Changes in prevalence and incidence of the major oral diseases; in Guggenheim B, Shapiro H (eds): Oral Biology at the Turn of the Century: Truth, Misconcepts and Challenges. Basel, Karger, 1998, pp 1-11.

Fejerskov O, Johnson NW, Silverstone LM: The ultrastructure of fluorosed human dental enamel. Scand J Dent Res 1974;82:357-372.

Fejerskov O, Larsen MJ, Richards A, Baelum V: Dental tissue effects of fluoride. Adv Dent Res 1994;8:15-31.

Fejerskov O, Manji F: Risk assessment in dental caries; in Bader JD (ed): Risk Assessment in Dentistry. Chapel Hill, University of North Carolina Dental Ecology, 1990, pp 214-217.

Fejerskov O, Nyvad B: Is dental caries an infectious disease? Diagnostic and treatment consequences for the practitioner; in Schou L (ed): Nordic Dentistry 2003 Yearbook. Copenhagen, Quintessence Publishing, 2003, pp 141151.

Fejerskov O, Scheie AA, Manji F: The effect of sucrose on plaque $\mathrm{pH}$ in the primary and permanent dentition of caries-inactive and -active Kenyan children. J Dent Res 1992;71:25-31. 
Fejerskov O, Silverstone LM, Melsen B, Møller IJ: Histological features of fluorosed human dental enamel. Caries Res 1975;9:190-210.

Fejerskov O, Thylstrup A, Larsen MJ: Clinical and structural features and possible pathogenic mechanisms of dental fluorosis. Scand J Dent Res 1977;85:510-534.

Fejerskov O, Thylstrup A, Larsen MJ: Rational use of fluoride in caries prevention: A concept based on possible cariostatic mechanisms. Acta Odontol Scand 1981;39:241-249.

Fitzgerald RJ, Keyes PH: Demonstration of the etiological role of streptococci in experimental caries in the hamster. J Am Dent Assoc 1960; 61:9-19.

Frazier PD, Little MF, Casciani FS: X-ray diffraction analysis of human enamel containing different amounts of fluoride. Arch Oral Biol 1967;12:35-42.

Granath L, Cleaton-Jones P, Fatti LP, Grossman ES: Prevalence of dental caries in 4- to 5-yearold children partly explained by presence of salivary mutans streptococci. J Clin Microbio 1993;31:66-70.

Groeneveld A: Longitudinal study of prevalence of enamel lesions in a fluoridated and non-fluoridated area. Community Dent Oral Epidemiol 1985;13:159-163.

Groeneveld A, Backer Dirks O: Fluoridation of drinking water, past, present and future; in Ekstrand J, Fejerskov O, Silverstone LM: Fluoride in Dentistry. Copenhagen, Munksgaard 1988, pp 229-251.

Hallsworth AS, Robinson C, Weatherell JA: The chemical pattern of carious attack. Caries Res 1971:5:16-17.

Hand JS, Hunt RJ, Beck JD: Incidence of coronal and root caries in an older adult population. $\mathrm{J}$ Public Health Dent 1988;48:14-19.

Hausen H: Caries prediction - state of the art Community Dent Oral Epidemiol 1997;25:8796.

van Houte J: Bacterial specificity in the etiology of dental caries. Int Dent J 1980;30:305-326.

Isaac S, Brudevold F, Smith FA, Gardner DE: The relation of fluoride in the drinking water to the distribution of fluoride in enamel. J Dent Res 1958;37:318-325.

Kay MI, Young RA, Posner AS: Crystal structure of hydroxy-apatite. Nature 1964;204:1050-1052.

Keyes PH: The infectious and transmissible nature of experimental dental caries: Findings and implications. Arch Oral Biol 1960;1:304-320.

Kiberstis P, Roberts L: It's not just the genes. Science 2002;296:685.

Kidd EAM, Thylstrup A, Fejerskov O, Bruun C: The influence of fluoride in surface enamel and degree of dental fluorosis on caries development in vitro. Caries Res 1980;14:196-202.

Koulourides T, Feagin FF, Pigman W: Remineralisation of dental enamel by saliva in vitro. Ann NY Acad Sci 1965;131:751-757.

Kuhn TS: The Structure of Scientific Revolution (1962), ed 2. Chicago, University of Chicago Press, 1970.

Kutnerian H, Kuyper AC: The influence of fluoride on the solubility of bone salt. J Biol Chem 1957;233:760-763.
Küseler A, Baelum V, Fejerskov O, Heidmann J: Accuracy and precision in vitro of Beetrode ${ }^{\circledR}$ microelectrodes used for intraoral $\mathrm{pH}$ measurements. Caries Res 1993;27:183-190.

Larsen MJ: Enamel Solubility Caries and Erosions; thesis Royal Dental College, Aarhus, 1975.

Larsen MJ, von der Fehr FR, Birkeland JM: Effect of fluoride on the saturation of an acetate buffer with respect to hydroxyapatite. Arch Oral Biol 1976;21:723-728.

Larsen MJ, Kirkegaard E, Poulsen S, Fejerskov O: Enamel fluoride, dental fluorosis and dental caries among immigrants to and permanent residents of five Danish fluoride areas. Caries Res 1986;20:349-355.

Last JM: A Dictionary of Epidemiology, ed 3. Oxford, Oxford University Press, 1995.

Laurence JR, Neu TR: Confocal laser scanning microscopy for analysis of microbial biofilms. Methods Enzymol 1999;310:131-144.

Loesche WJ: Role of Streptococcus mutans in human dental decay. Microbiol Rev 1986;50: 2118-2135.

Luan W-M, Baelum V, Fejerskov O, Chen X: Tenyear incidence of dental caries in adult and elderly Chinese. Caries Res 2000;34:205-213.

Manley RS, Harrington DP: Solution rate of tooth enamel in acetate buffer. J Dent Res 1959;38: 910-919.

Margolis HC, Duchworth JH, Moreno EC: Composition of pooled resting plaque fluid from caries-free and caries susceptible individuals. J Dent Res 1988;67:1468-1475.

Marsh PD: Microbial ecology of dental plaque and its significance in health and disease. Adv Dent Res 1994;8:263-271.

Marsh PD, Martin M: Oral Microbiology, ed 3. London, Chapman \& Hall, 1992.

Matee MIN, Mikx FHM, De Soet JS, Maselle SY, De Graaff J, Van Palenstein Helderman WH: Mutans streptococci in caries-active and cariesfree infants in Tanzania. Oral Microbiol Immunol 1993;8:322-324.

Mellberg JR: Enamel fluoride and its anticaries effects. J Prevent Dent 1977;4:8-20.

Newsely JW, McConnell D, Armstrong WD: The nature of carbonate contents in tooth mineral. Experientia 1963;19:620-621.

Nyvad B, Fejerskov O: Structure of dental plaque and the plaque-enamel interface in human experimental caries. Caries Res 1989;23:151158.

Nyvad B, Kilian M: Comparison of the initial streptococcal microflora on dental enamel in caries-active and in caries-inactive individuals. Caries Res 1990;24:267-272.

Øgaard B, Rølla, Ruben J, Dijkman T, Arends J: Microradiographic study of deminerlization of shark enamel in a human caries model. Scand $\mathbf{J}$ Dent Res 1988;96:209-211.

van Palenstein Heldermann WH, Mikx FHM, van't Hof MA, Truin GJ, Kalsbeek H: The value of salivary bacterial counts as a supplement to past caries experience as caries predictor in children. Eur J Oral Sci 2001;109:312-315.

Planck M: Scientific Autobiography and Other Papers (translated by Gaynor F). New York, 1940.
Poulsen S, Larsen MJ: Dental caries in relation to fluoride content of enamel in the primary dentition. Caries Res 1975;9:59-65.

Richards A, Fejerskov O, Baelum V: Enamel fluoride in relation to severity of human dental fluorosis. Adv Dent Res 1989;3:147-153.

Richards A, Kragstrup J, Josephsen K, Fejerskov $\mathrm{O}$ : Dental fluorosis developed in post-secretory enamel. J Dent Res 1986;65:1406-1409.

Richards A, Larsen MJ, Fejerskov O, Thylstrup A: Fluoride content of buccal surface enamel and its relation to dental caries in children. Arch Oral Biol 1977;22:425-428.

Richards A, Likimani S, Baelum V, Fejerskov O: Fluoride concentrations in unerupted fluorotic human enamel. Caries Res 1992;26:328-332.

Rodriques FE: Quantitative incidence of Lactobacillus acidophilus in the oral cavity as a presumptive index of susceptibility to dental caries. J Am Dent Assoc 1931;18:2118-2135.

Schamschula RG, Agus H, Charlton G, Duppenthaler JL, Un P: Associations between fluoride concentration in successive layers of human enamel and individual dental caries experience. Arch Oral Biol 1979;24:847-852.

Shern RJ, Driscoll WS, Korts DC: Enamel biopsy results of children receiving fluoride tablets. J Am Dent Assoc 1977;95:310-314.

Smith CE: Cellular and chemical events during enamel maturation. Crit Rev Oral Biol Med 1998;9:128-161.

Spector PC, Curzon MEJ: Surface enamel fluoride and strontium in relation to caries prevalence in man. Caries Res 1979;113:227-230.

Stephan RM: Changes in hydrogen-ion concentration on tooth surfaces and in carious lesions. J Am Dent Assoc 1940;27:718-723.

Sullivan ̊̊, Borgström MK, Granath L, Nilsson G: Number of mutans streptococci or lactobacilli in a total dental plaque sample does not explain the variation in caries better than the numbers in stimulated whole saliva. Community Dent Oral Epidemiol 1996;24:1559-163.

Sullivan ^, Granath L, Widenheim J: Correlation between child caries incidence and $S$. mutans/ lactobacilli in saliva after correction for confounding factors. Community Dent Oral Epidemiol 1989;17:240-244.

Tanzer JM: On changing the cariogenic chemistry of coronal plaque. J Dent Res 1989;68(special issue):1576-1587.

Thylstrup A: Clinical Evaluation of Fluoride Derived Enamel Changes: A Critical Review; thesis Royal Dental College, Aarhus, 1979.

Volker JF: Effect of fluoride in solubility of enamel and dentin. Proc Soc Exp Biol Med 1939;42: 725-727.

Weatherell JA, Robinson C, Hallsworth AS: The concept of enamel resistance: A critical review in Guggenheim B (ed): Cariology Today. Basel, Karger, 1984, pp 223-230.

Young RA: Biological apatite vs. hydroxyapatite at the atomic level. Clin Orthop 1975;113:249262.

Zipkin I, Posner AS, Eanes ED: The effect of F on $\mathrm{x}$-ray diffraction pattern of apatite of human bone. Biochim Biophys Acta 1962;59:255258. 